\title{
GOVERNAMENTALIDADE ALGORÍTMICA E AS SUBJETIVAÇÕES RAREFEITAS*
}

\author{
Edson Teles***** \\ edsonteles@gmail.com
}

RESUMO O artigo tem como objetivo problematizar a racionalidade de governo gerida pelos algoritmos. Argumentar-se-á que a governamentalidade, tal como definida por Michel Foucault, a saber, uma lógica de cálculos e estatísticas utilizada para conduzir a ação dos individuos, mesclada às funções das máquinas autônomas, configura um novo regime de produção de subjetividades. Estruturando as relações entre o humano e a máquina em velocidade instantânea e acessando o máximo de informações sobre os interesses e necessidades dos individuos, a governamentalidade algoritmica trabalha com a ideia de uma normatividade imanente ao próprio deslocamento e circulação dos dados, bloqueando experiências sociais e políticas com a eliminação das esferas de debates e criação do comum.

Palavras-chave Michel Foucault, algoritmos, perfil, normatividade, dispositivo.

ABSTRACT The article aims to problematize the rationality of government managed by the algorithms. It will be argued that governmentality, as defined by Michel Foucault, namely a logic of calculations and statistics used to conduct the action of individuals, merged with the functions of autonomic machines, sets up a new regime of production of subjectivities. Structuring the relations between human and machine at instantaneous speed and accessing as much information about the interests and needs of individuals, algorithmic governmentality

* Artigo submetido em 10/01/17. Aceito em 15/03/17.

** Universidade Federal de São Paulo/Unifesp. Guarulhos - SP - Brasil.

*** Pesquisa realizada com apoio da Fapesp, Processo 2015/22723-0. 
works with the idea of a normativity immanent from the own displacement and circulation of the data, blocking social and political experiences with the elimination of the spheres of debate and creation of the common.

Keywords Michel Foucault, algorithms, profile, normativity, dispositive.

Imagine-se combinando com amigos, via celular, uma saída noturna. Vocês pensam em cinema, talvez uma janta ou cerveja. Enfim, qualquer diversão que promova o encontro e a boa conversa. Após a pesquisa no buscador preferido e feita a escolha entre as opções oferecidas, vocês inserem o nome do estabelecimento no aplicativo de localização e, em seguida, chamam o serviço de transporte. $\mathrm{O}$ valor da corrida será debitado no cartão de crédito. Nestes minutos de utilização de aplicativos e outros serviços via Internet, com alguma passagem nas redes sociais, enormes bases de dados receberam e transmitiram informações em torno de suas movimentações. Perante este acúmulo de entradas e saídas de dados, o indivíduo realiza seus desejos sob o custo de tornar-se mera engrenagem. As máquinas, cujas nuvens de informações pairam através, sobre e entre nossas vidas, mitigam as distâncias entre os mundos físico e virtual, acionando e satisfazendo necessidades coletivas e singulares.

Certa autonomia das máquinas, indo de um usual laptop até os mais sofisticados sistemas de segurança por sensores e câmeras, é hoje um fato. A definição de seu funcionamento é de difícil objetificação, contudo, sua presença é notável. Encontra-se em diferentes artefatos, mas assemelha-se mais a uma "visão", um "regime da visibilidade e da inteligibilidade" dos corpos e suas experiências (Rouvroy, 2011, p. 121). Por meio das mais variadas tecnologias, a computação autônoma de dados acessa, traduz e classifica gestos, relacionamentos, subjetividades e individualidades em tempo imediato, capturando as mais sensíveis ou rústicas variações. Define-se a autonomia das máquinas por sua capacidade de autoconhecimento, pela dinâmica de ajuste próprio diante do imprevisto, otimização com autoprevenção, reparação do mau funcionamento e capacidade de adaptação ao ambiente e seus processos.

A infraestrutura com múltiplos modos de observação, automatização de funções, ambientes interativos e inteligentes das novas tecnologias tende a proporcionar formas de vida mais fáceis, confortáveis, prazerosas e eficientes. Há ganhos no fato de as máquinas detectarem, avaliarem e, principalmente, anteciparem desejos e interesses, conhecendo as preferências e as redes de relações. Customizando as necessidades de acordo com as ofertas e serviços 
e construindo um perfil individualizado, fornece a impressão de nos conhecer melhor do que nós mesmos. Ademais, permite a identificação do que não se deseja, evitando a perda de tempo, colocando-nos em segurança em relação às ameaças da urbanidade violenta, produzindo outras possibilidades sociais. Ser observado, dentro de uma ideologia da objetividade dos procedimentos autômatos das máquinas, tem o aspecto de uma seletiva tecnologia de segurança e serviços.

Entretanto, não é de interesse deste artigo enumerar os diferentes sistemas e suas máquinas, nem abordar as mais recentes tecnologias. Nossa intenção é introduzir o debate filosófico acerca das características do que seria um novo modo de lidar com as subjetivações contemporâneas. Da interação entre as subjetividades e as tecnologias autônomas. Interessa-nos como os indivíduos passam a ser objetos da observação, classificação e predição de sociabilidades. Buscaremos debater como estas máquinas autônomas, ao traduzirem e predizerem o mundo físico e seus costumes, hábitos, idiossincrasias, gostos e atos geram novos regimes de subjetivação, ou a rarefação desses processos. O pressuposto inicial é o de que não há neutralidade nesta tradução, mas que na circulação massiva de dados ocorre a atualização e a transformação de uma racionalidade governamental.

\section{Entre o discursivo e a política algorítmica}

Nem Hannah Arendt, para quem o mundo contemporâneo caracterizou-se pela perda das experiências, afetivas e existenciais, teria imaginado um modo tão tecnológico de anulação do indivíduo e de suas subjetividades. Segundo ela, na medida em que atos e pensamentos se configuravam como um "cálculo de consequências", uma espécie de "função do cérebro", "a ação logo passou a ser, e ainda é, concebida em termos de produzir e de fabricar", lançando o humano em "um funcionamento puramente automático, $[\ldots]$ entorpecido e 'tranquilizado' de comportamento" (Arendt, 2010, pp. 402-403). Como em uma narrativa de ficção científica, Arendt imagina a cena em que os indivíduos perdem sua condição de serem fundamentalmente separados das coisas, naturais ou artificiais, e "[...] os corpos humanos começam gradualmente a ser revestidos por uma carapaça de aço" (ibidem, p. 404). ${ }^{1}$

1 A divisão formulada pela filosofia moderna entre o que é por natureza e o que é por fabricação se desfaz no contemporâneo, seja devido ao fato de a filosofia localizar tais elementos entre os híbridos, aqueles que são quase humanos e, ao mesmo tempo, quase objetos; seja devido ao surgimento de tecnologias que tornam a separação natureza/cultura algo meramente discursivo. Segundo Bruno Latour, "tanto do lado da natureza quanto do lado do social, não podemos mais reconhecer as duas garantias constitucionais dos modernos: as leis universais das coisas, os direitos imprescritiveis dos sujeitos" (2013, p. 54). 
Se nos processos político-discursivos ${ }^{2}$ a legitimidade, a história, a verdade, a justiça representam elementos mobilizadores, organizadores e hierarquizantes da ação, há uma esfera do contemporâneo transitando em outras características e estratégias. Não se trata de projetar uma ação política sem os universais da política moderna (representação, soberania, direito, Estado), mas de compreender uma política fundamentalmente exercida por meio de máquinas e dispositivos de controle das subjetivações combinados com lógicas de governo.

As transformações engendradas pela produção de subjetividades não se apresentam como resultado apenas do conhecimento, da cultura ou da informação. Sua dimensão seria também afetiva e existencial. Com base nesta produção se propagariam discursos, saberes e funções político-tecnológicas. Félix Guattari assim define este "coquetel subjetivo contemporâneo":

Do mesmo modo que as máquinas sociais que podem ser classificadas na rubrica geral de Equipamentos Coletivos, as máquinas tecnológicas de informação e de comunicação operam no núcleo da subjetividade humana, não apenas no seio de suas memórias, da sua inteligência, mas também da sua sensibilidade, dos seus afetos, dos seus fantasmas inconscientes (2012, p. 14).

Assim, acrescentaríamos à política jurídico-representativa da soberania uma ação relacional, abrangendo os regimes de produção de subjetividades. Pensamos, com Michel Foucault, no agir político enquanto [1] estratégias gerais de poder, procurando saber "por onde isso passa, como se passa, entre quem e quem, entre que ponto e que ponto, segundo quais procedimentos e com quais efeitos" (2008, p. 4). Refletimos sobre [2] um conjunto de mecanismos e procedimentos cujas funções seriam as de manter relações de poder inalteradas ou tendentes a fortalecerem os processos de dominação e controle. É por isso que não buscaremos entender o que isto é, mas compreender as relações entre forças em disputa, sem que se faça a distinção destas com os seus mecanismos. Nesse contexto, entende-se por relações a operação que liga A a B, de modo

2 A tradição teórica tem pensado a política como o exercício dos discursos e gestos, quando ato e palavra singulares dos indivíduos ou grupos políticos buscam persuadir maiorias com o fito de transformar o futuro. O argumento desta tradição, separando as coisas da natureza e as fabricadas pelas relações sociais, pensa "os homens no plural, isto é, os homens na medida em que vivem, se movem e agem neste mundo, [e] só podem experimentar a significação porque podem falar uns com os outros e se fazer entender aos outros e a si mesmos" (Arendt, 2010, p. 5). Seguindo à divisão moderna entre objetos e sujeitos, Jacques Rancière fará a síntese de um agir essencialmente discursivo. Para ele, é preciso observar três aspectos na política: primeiro, é necessário haver uma esfera de aparência do povo, um "campo da experiência, de um visível que modifica o regime do visível"; segundo, o povo da aparência não pertence à unidade de grupos determinados, pois "a democracia é a instituição de sujeitos que não coincidem com partes do Estado ou da sociedade", o sujeito não identitário; e, terceiro, o palco no qual o povo se exibe é o lugar do conflito social, não entre partes, mas um litígio que põe em jogo a própria situação de conflito (1996, pp. 102-103) 
que o conteúdo destes elementos não seja o mais importante. Não existem os mecanismos e procedimentos da ação política e, em outra dimensão, os acontecimentos e as relações efetivadas por eles. A ação política são mecanismos de técnicas e tecnologias de poder e suas relações.

Nas novas relações de poder as modificações também implicaram "na reativação e na transformação das técnicas jurídico-legais e das técnicas disciplinares". Portanto, não há uma sucessão de modos de operação do poder, mas adições e atualizações, sendo o investimento na lógica de governo "uma certa maneira de acrescentar, de fazer funcionar, além dos mecanismos propriamente de segurança, as velhas estruturas da lei e da disciplina" (ibidem, pp. 13-14) ${ }^{3}$.

Com base na ideia de que governar é a ação de condução das ações dos outros e das coisas, estabeleceu-se uma dinâmica de cálculos baseados na observação dos fenômenos populacionais e dos fatos relacionados a estes eventos. De posse de uma série de dados e probabilidades regulares, podem-se fabricar políticas de otimização da capacidade de controle, objetivando produtividade e aumento do capital. Não são funções específicas dos indivíduos, nem apenas dos regimes de produção de subjetividades, mas saídas e entradas, inputs e outputs, nos processos geridos e governados pelas tecnologias. Não seria o fim do indivíduo, nem mesmo sua dessubjetivação. Porém, a anulação das subjetividades, ${ }^{4}$ congelando sujeitos em suas bolhas discursivas, ideológicas e identitárias.

$\mathrm{Na}$ esteira da problemática do governo, por meio de estatísticas temos as coletas de dados em larga escala, com conteúdos múltiplos e sendo produzidos

3 "Um pensador como Michel Foucault analisara dois tipos de sociedades bastante próximas de nós: as sociedades de soberania e as sociedades disciplinares. A passagem típica de uma sociedade de soberania para uma sociedade disciplinar coincidiu, segundo ele, com Napoleão. A sociedade disciplinar definia-se - as análises de Foucault, com todo mérito, por causa disso tornaram-se famosas - pela constituição de meios de enclausuramento: prisões, escolas, oficinas, hospitais. As sociedades disciplinares tinham necessidade disso. Essa análise engendrou ambiguidades em certos leitores de Foucault, pois se pensou que essa era sua última palavra. Evidentemente que não. Foucault jamais pensou, e ele o disse com bastante clareza, que as sociedades disciplinares fossem eternas. Antes, ele pensava que entraríamos num tipo de sociedade nova. É claro que existe todo tipo de resquício de sociedades disciplinares, que persistirão por anos a fio, mas já sabemos que nossa vida se desenrola numa sociedade de outro tipo, que deveria chamar-se, segundo o termo proposto por William Burroughs - e Foucault tinha por ele uma viva admiração -, de sociedades de controle" (Deleuze, 1999, p. 12). Burroughs foi um dos artistas que participou do evento "Schizo-Culture", em novembro de 1975, na Columbia University (EUA). Lá apresentou seu paper "The Limits of Control”, em debates com Foucault, Deleuze, Guattari, Lyotard, John Cage, Philip Glass e Jack Smith, entre outros. Sua ideia central era a de que o controle somente seria possível por meio de uma política de concessão, ou de uma liberação dos indivíduos. Cf. "Schizo-Culture. The Event, The Book" (Lotringer e Morris, 2014).

4 Com o advento da televisão, já se fez perceptível um modo de implicação das tecnologias sobre as subjetividades, provocando o congelamento de suas possibilidades e aberturas. Para Paul Virilio (2006), há uma ideia de "realidade" transmitida por meio da imagem televisiva que condiciona falas e interações sociais a ponto de modificar as subjetivações, suscitando "uma sincronização dos afetos e de suas emoções". É o que ele chama de "tele-objetividade", uma "realidade" que se torna dado objetivo de governo. Ocorreria um estreitamento do espaço e do tempo de vivências, provocando a perda de experiências subjetivas. 
em alta velocidade. São os Big Data. Estes novos dispositivos ${ }^{5}$ permitem reduzir o investimento de controle no indivíduo médio ou normal, como se valoriza na tradicional normatização social, propiciando uma ação sobre os processos e o meio ambiente. Pode-se acessar a "realidade" de um território, grupo, instituição, mercado, país em micropartes de segundos. Dito de outra forma, apreende-se a realidade de modo imediato e imanente. As informações viriam ao mesmo passo em que são produzidas e, sequencialmente e de modo quase instantâneo, se tornariam funções de governo. As relações entre a entrada e a saída das informações seriam o próprio processo político em andamento.

Para se transformar dados em práticas de governo, acionam-se os datamining. Como em um espremedor de frutas, extraem-se dados em situação bruta a seiva que interessam a determinada modelagem de comportamentos. Das massivas acumulações de dados começam a emergir saberes estatísticos oriundos das correlações de informações não selecionadas, não classificadas e não hierarquizadas, altamente heterogêneas. Com o máximo de automação, reduzindo a intervenção humana e dispensando o uso de hipóteses ou convenções prévias, esquiva-se das subjetividades e das normas discursivas. ${ }^{6} \mathrm{O}$ funcionamento dos Big Data e dos datamining a partir de um sistema de relações não se submete a qualquer média e mantém autonomia diante das normas sociais. "Esta emancipação em relação a toda forma de média associa-se, notadamente, ao caráter autodidata destes dispositivos e pode ser considerada como essencial à ação normativa contemporânea" (Rouvroy e Berns, 2015, p. 38).

Aparentemente sem qualquer intervenção, a objetividade e a veracidade dos resultados obtidos por meio dos Big Data parecem chegar ao seu grau máximo, pois suas hipóteses são os próprios dados em circulação. Assemelhase ao diagrama foucaultiano, tal como comentado por Gilles Deleuze:

5 Para Michel Foucault, o dispositivo, em seu caráter estratégico e funcional, visa lidar com uma tensão, podendo ser para conduzir as relações de forças, ou para bloqueá-las e delas fazer uso. Em entrevista concedida em 1977, ele comenta o termo: "Aquilo que procuro destacar com este nome é, primeiramente, um conjunto absolutamente heterogêneo que implica discursos, instituições, estruturas arquitetônicas, decisões regulamentares, leis, medidas administrativas, enunciados científicos, proposições filosóficas, morais e filantrópicas, em resumo: tanto o dito como o não dito, eis os elementos do dispositivo. O dispositivo é a rede que se estabelece entre estes elementos. [...] O dispositivo tem uma função eminentemente estratégica. [...] Trata de uma certa manipulação de relações de força, de uma intervenção racional e combinada das relações de força, seja para desenvolvê-las em certa direção, seja para bloqueá-las, ou para estabilizá-las, utilizá-las" (Foucault, 2001, pp. 299-300, tradução nossa).

6 Não se trata de desconsiderar as normas sociais, ou as intenções humanas embutidas nas máquinas e nas tecnologias de relações. "Mesmo que, a partir deste momento, as máquinas se tornem cada vez mais 'autônomas' e 'inteligentes', elas continuam, certamente, dependentes de seu design inicial, das intenções, scripts ou cenários em função dos quais elas foram imaginadas. Elas são, desde sua concepção (e quaisquer que sejam as formas que elas assumam em seguida), portadoras de visões do mundo, expectativas e projeções conscientes ou inconscientes de seus conceituadores" (Rouvroy e Berns, 2015, p. 37). 
O diagrama não é mais o arquivo, auditivo ou visual, é o mapa, a cartografia, coextensiva a todo o campo social. É uma máquina abstrata. Definindo-se por meio de funções e matérias informes, ele ignora toda distinção de forma entre um conteúdo e uma expressão, entre uma formação discursiva e uma formação não-discursiva. É uma máquina quase muda e cega, embora seja ela que faça ver e falar (2006, p. 44).

Em um trabalho estatístico tradicional, as informações obtidas são o resultado de filtros e convenções advindas de debates e conflitos, podendo ser questionadas pelas subjetividades envolvidas, em especial pelas que as operam enquanto cálculos de governo. A estatística clássica possui características diferentes das probabilidades algorítmicas das grandes bases de dados. Ela objetiva a confirmação de hipótese previamente colocada. Posta a ideia a ser confirmada, a estatística clássica irá selecionar os dados sobre os quais trabalhará. Após a objetificação dos dados a partir de uma temática, ocorre a quantificação dos números em cifras de comparação. Será feita uma avaliação negativa ou positiva da hipótese proposta a partir de convenções muitas vezes controversas e com significações diferentes segundo o ponto de vista de quem as opera.

Já nos Big Data, não há hipóteses prévias, pois se procura diretamente na correlação dos dados a expressão dos fenômenos. As relações estatísticas dos datamining esquivam-se das normas sociais de seleção, classificação e hierarquização dos dados, transitando diretamente entre o real das informações e a operação destas via seus elementos técnicos e tecnológicos. A realidade ganha uma aparência de esfera pública, porém controlada por interesses particulares e com governos e empresas coletando quantidades massivas de dados não classificados. Eles podem vir de redes sociais, blogs, feeds de notícias, dados de sensores de faces, sons e imagens, ${ }^{7}$ e-mails, jogos, ${ }^{8}$ geolocalizadores e autorizações de celulares, sistemas de cartões, operações de marketing e publicidade, pesquisas científicas, redes e sistemas de segurança. ${ }^{9}$ Este volume astronômico de dados,

7 Um bom exemplo é o aplicativo DeepFace, desenvolvido pela face.com, uma empresa israelense (o Estado laboratório da indústria militar de segurança) e utilizado pelo Facebook para taguear o rosto de seus usuários, com ou sem consentimento. A adesão a esta tecnologia se dá justamente para garantir a segurança do usuário caso sua imagem comece a circular em quantidade ou local indesejável. O aplicativo localizaria o problema, avisaria o usuário e este teria a ferramenta para borrar a imagem. Sob o manto do discurso da segurança o indivíduo adere à produção de seus "traços".

8 Por meio de dados de entretenimento, há estratégias de controle e governo dos indivíduos e das coisas, como é o caso do jogo Pokémon Go. Enquanto o usuário captura monstrinhos, a Niantic Inc, desenvolvedora do programa, coleta via senha da conta Google dados de e-mail, redes sociais, consumo eletrônico, os quais são cruzados com a localização do indivíduo, onde come, estuda, mora, qual transporte utiliza, tempo gasto em cada lugar. Qualquer parte do mundo pode ser geomapeada, em mínimos detalhes e correlações, e as informações coletadas se misturarem com várias outras em imensos Big Data.

9 O programa e-Borders, financiado pelo Reino Unido e desenvolvido pela megacorporação da indústria bélica Raytheon, é um modelo de dispositivo algorítmico de segurança. Tratava-se de um sistema de recolhimento de informações das empresas de transporte que seriam alocadas em uma grande base de dados. A partir daí teriam suas informações cruzadas às de serviços de fronteiras, vistos biométricos, reconhecimento facial 
todos eletronicamente armazenados e acessíveis de qualquer lugar e a qualquer momento - óbvio que não por qualquer pessoa ou sistema de coleta de dados -, podem ser inseridos por indivíduos voluntariamente, ou em resposta a alguma demanda, cedidos ou simplesmente abandonados. De fato, são mais dados "deixados" do que "transmitidos". Ainda assim, não aparecem como subtraídos sem autorização, pois aparentam estarem dispersos e em lugares quaisquer.

As funções algorítmicas têm a característica de produzirem mecanismos de controle sem a necessidade de acionar discursos e ideologias como estratégias centrais de governo. Enquanto os dados entram e saem em big quantidades, velocidades e variedades, e os elementos da operação se inserem em funções sem debates ou discordâncias, os discursos são mantidos dentro de bolhas, cada vez mais fechadas e direcionadas. Para alguns pesquisadores este modo de correlação produz a radicalização das opiniões e a fragilidade das experiências comuns (Sustein, 2009).

\section{O governo da circulação e dos meios}

A condução da ação dos indivíduos por meio de funções, em torno dos Big Data, pode ser nomeada como "governamentalidade algorítmica". ${ }^{10}$ Ela se fundamenta no conceito de governamentalidade, em Michel Foucault, notadamente no seminário "Segurança, Território, População" (1977-1978), acrescido e transformado pelas funções algorítmicas.

Michel Foucault denominou governamentalidade os procedimentos e cálculos que têm por alvo a vida de uma população. Segundo o filósofo, a adoção desse tipo de governo foi o modo astuto com que o Estado moderno se permitiu sobreviver por meio "de um poder que se exerce mais sobre uma multiplicidade do que sobre um território" (2008, p. 173). A lógica desta estratégia consiste

e inserção nas cidades (locais de trabalho e moradia etc.). O discurso do Ministério do Interior era o de que com o sistema se reduziria quase totalmente o risco de um terrorista entrar no país. Por mais "escondido" que ele estivesse, algum rastro de seus dados apareceria ao minerar as grandes bases de dados. Segundo consta, o programa não foi adiante pois, aparentemente, não houve dinheiro suficiente. Porém, segundo a auditoria feita pela National Audit Office (NAO), ligada ao Parlamento britânico, houve mau uso da verba e com resultado aquém do contratado. É curioso que no "Relatório da NAO" se fale que os dados da contabilidade do projeto, entre os anos de 2003 e 2006, simplesmente desapareceram devido a uma mudança de sistema de procedimentos no armazenamento de dados.

Cf. "E-borders and successor programmes" [Online]. Disponível em https://www.nao.org.uk/wp-content/ uploads/2015/12/E-borders-and-successor-programmes.pdf (Acessado em 28 de novembro de 2016).

10 O termo "governamentalidade algorítmica" foi cunhado, entre os anos de 2011 e 2013, pela filósofa do direito Antoinette Rouvroy. No seu artigo "Technology, virtuality and utopia" (2011), ela anuncia uma "racionalidade governamental" animada pela "computação autônoma". Nesse texto a autora ainda não utilizava o termo "algoritmo" colado ao "governamentalidade". Na conferência "Algorithmic Governmentality and the End(s) of Critique” (2013), o termo já aparece tal como apresentamos aqui. 
em "trabalhar na realidade, fazendo os elementos da realidade atuarem uns em relação aos outros, graças a e através de toda uma série de análises e disposições específicas" (ibidem, p. 62). Teríamos com os dispositivos de governo uma tecnologia ou uma "física de poder", de cunho liberal e economicista:

Uma física do poder ou um poder que se pensa como ação física no elemento da natureza e um poder que se pensa como regulação que só pode se efetuar através de e apoiando-se na liberdade de cada um, creio que isso aí é uma coisa absolutamente fundamental. Não é uma ideologia, não é propriamente, não é fundamentalmente, não é antes de mais nada uma ideologia. É primeiramente e antes de tudo uma tecnologia de poder, é em todo caso nesse sentido que podemos lê-lo (ibidem, p. 64).

Nos procedimentos da governamentalidade, além de atos acionados via ordenamento jurídico, haverá todo um cálculo sobre a incidência de um acontecimento, ${ }^{11}$ o quanto ele interfere na vida social, qual seria o custo de gestá-lo. O dispositivo, primeiro, toma ciência do ocorrido a partir de suas probabilidades (não um fato em si, mas a ocorrência dele enquanto fenômeno). Após, faz o cálculo dos custos, caso se efetive ou seja bloqueado, e fixa uma média de como é possível proceder.

A condução da vida e dos corpos atua em uma determinada quantidade e qualidade de meios onde se identifica um acontecimento do qual se possam extrair dados regulares e suscetíveis de entrarem em jogos de probabilidade. Não se determina o espaço, atua-se sobre algo dado. Pode ser uma manifestação política, a venda de algum produto comercial, o acesso ao sistema público de saúde. Atua no sentido de aumentar, o quanto possível, os índices positivos e produtivos e, simultaneamente, diminuir o impacto do que seja risco à ordem. Age sobre as séries, as regularidades estatísticas, e busca levar em conta o que pode acontecer. Assim, seu mecanismo não é de única função ou forma processual. Adapta-se ao fenômeno, de modo multifuncional e a depender da demanda. "O meio é certo número de efeitos, que são efeitos de massa que agem sobre todos os que aí residem" (ibidem, p. 28). Trata-se do controle mais da circulação e das relações, do que dos indivíduos e de seus discursos:

11 Michel Foucault concebia o acontecimento como uma física imaterial que seria a própria relação: "Certamente o acontecimento não é nem substância nem acidente, nem qualidade nem processo; o acontecimento não é da ordem dos corpos. Entretanto, ele não é imaterial; é sempre no âmbito da materialidade que ele se efetiva, que é efeito; ele possui seu lugar e consiste na relação, coexistência, dispersão, recorte, acumulação, seleção de elementos materiais; não é o ato nem a propriedade de um corpo; produz-se como efeito de e em uma dispersão material. Digamos que a filosofia do acontecimento deveria avançar na direção paradoxal, à primeira vista, de um materialismo do incorporal" (1996, pp. 57-58). 
Circulação entendida, é claro, no sentido bem amplo, como deslocamento, como troca, como contato, como forma de dispersão, como forma de distribuição também, sendo o problema o seguinte: como é que as coisas devem circular ou não circular? [...] Deixar as circulações se fazerem, controlar as circulações, separar as boas das ruins, fazer que as coisas se mexam, se desloquem sem cessar, que as coisas vão perpetuamente de um ponto a outro, mas de uma maneira tal que os perigos inerentes a essa circulação sejam anulados (Ibidem, pp. 84-85).

Os dispositivos atuariam para deixar acontecer, não interferindo até um certo nível e aproveitando-se da força dos acontecimentos como forma de controlá-los e conduzi-los. Compreende-se as ínfimas características dos fatos, das ações e das subjetividades como processos necessários, dados de realidade, nem positivos, nem negativos.

Este modo de governar efetivado por meio de algoritmos designa "globalmente um certo tipo de racionalidade (a)normativa ou (a)política que repousa sobre a coleta, agregação e análise automatizada de dados em quantidade massiva de modo a modelizar, antecipar e afetar, por antecipação, os comportamentos possíveis" (Rouvroy e Berns, 2015, p. 42). Há uma descentralização do indivíduo, diminuindo o papel das subjetivações comuns às formas discursivas de ação política. Os Big Data dispensam a identificação do indivíduo para conduzir circulações e relações. Funcionam em um fluxo no qual "não se enclausuram pessoas, mas, ao fazer estradas, multiplicam-se os meios de controle. Não digo que esse seja o único objetivo das estradas, mas as pessoas podem trafegar até o infinito e 'livremente', sem a mínima clausura, e serem perfeitamente controladas" (Deleuze, 1999, p. 12). Os fluxos e deslocamentos produzem normatividades, bem como estas implicam mais circulações. Neste sentido, quanto mais caminhos forem produzidos, maior será a "livre" circulação e mais normas serão ativadas.

Na obra "O normal e o patológico", Georges Canguilhem mostra como o patológico se designa a partir do normal, indicando que a doença não seria uma experimentação vivida, mas uma derivação da vida já estabelecida na normatividade. ${ }^{12}$ Para o autor, a patologia se revelaria a partir da relação do organismo com o seu meio ambiente. Vincular o normal e o patológico a partir de uma relação com o meio implica afirmar que não há uma doença em

12 As definições da razão clínica, que guiam as leituras acerca das patologias compreendem o corpo como um volume orgânico universal e mensurável, fornecendo um padrão de objetividade e de cálculo das anormalidades. Contudo, para Canguilhem, há uma outra forma de identificação da doença, fundamentada na ideia grega de equilibrio dinâmico e funcional, de modo que uma perturbação ao equilibrio do corpo seria a doença. Esta se apresenta como um acontecimento único, relacionado com a harmonia dos organismos e impossível de ser tratado por meio da localização de um único órgão ou tecido específico. "É claro que se pode fazer experiência com cada mecanismo funcional separadamente. No entanto, no organismo vivo todas as funções são interdependentes e seus ritmos harmonizados" (2002, p. 61). 
si, mas uma descontinuidade entre o equilíbrio e o desequilíbrio. Rompe-se o vínculo entre doença e anomalia, sendo esta última uma correlação entre o organismo e o meio, podendo inclusive produzir uma estratégia de vida mais qualificada para o corpo individual. "Não existe fato que seja normal ou patológico em si. A anomalia e a mutação não são, em si mesmas, patológicas. Elas exprimem outras normas de vida possíveis". Se as normas observadas forem inferiores às anteriores serão consideradas patológicas, mas se forem equivalentes ou superiores serão consideradas normais. "Sua normalidade advirá de sua normatividade" (Canguilhem, 2002, p. 113).

Para a governamentalidade há uma normatividade imanente advinda das correlações com o meio ambiente. O organismo não é suporte e produto, como no poder disciplinar, nem objeto, como no ordenamento jurídico. Haveria mesmo um fluxo constante de relações no qual o corpo do indivíduo é o próprio meio, parte constitutiva dele. ${ }^{13}$ Em um fluxo imanente, a normatividade oriunda do meio não seria uma mera cadeia de ações e reações, como na física newtoniana. Seguindo a argumentação de Canguilhem e adaptando-a à governamentalidade, certa normatividade surgiria a partir de operações cujas funções são atualizadas pelos algoritmos. O desvio ou a não operação nos valores determinados enquanto anomalia configura-se como "falha" ou "erro", alimentando as informações do algoritmo e redefinindo os fluxos tão imediatamente quanto a "realidade" é lida pelas máquinas. ${ }^{14}$ Neste sistema de controle e condução, a falha desaparece ao ser interpretada e reassimilada, tornando-se um dado de refinação da modelagem de perfis e comportamentos.

\section{Esterilizando os processos de subjetivação}

A governamentalidade mantém a aparência de estar sob a "democracia" da heterogeneidade, da multiplicidade e do anonimato como formas imanentes das "livres" correlações de dados. O espaço público estaria garantido pelo amplo acesso ao meio virtual e à conectividade à Internet, sem a necessidade de debater sob quais interesses se encontra sua gestão. Não haveria, nestas máquinas de governo, o uso das referências classistas, racistas, ideológicas, religiosas, de gênero. Não seria mais a política da exclusão do anormal, daquele que escapou à média das normas sociais, mas a de evitar o imprevisível sob a garantia de "liberdade" para cada um ser plenamente quem de fato é.

13 Para aprofundar a problematização da normatividade imanente em Canguilhem, ver o texto "Normatividade vital e errância", de Vladimir Safatle (2015), incluído em seu livro "O circuito dos afetos".

14 O aplicativo Waze, de condução da circulação de veículos, considera a "falha" ou "erro" como um dado da realidade e, quando ocorre um acidente de trânsito, imediatamente o aplicativo assimila o imprevisto e traça uma nova rota. 
A racionalidade governamental se alimentaria de dados objetivos, aparentemente insignificantes e sem a marca do sujeito. Criam-se modelos de comportamento sem que o indivíduo perceba a condução de suas ações pelas funções acionadas via algoritmos. E quanto mais se utiliza dos dispositivos tecnológicos, mais se potencializa o governo e sobre uma mais ampla gama de grupos e indivíduos ela produz efeitos.

Trata-se de mecanismos e táticas não intencionais e de máquinas a-significantes ${ }^{15}$ de rastreamento não do ato do indivíduo "perigoso", mas de identificação das incertezas na condução das relações de força. Não se busca o bandido, o drogado, o terrorista, o militante político, o pobre, ou qualquer um dos anormais sociais. O alvo não é mais o indivíduo, o conteúdo de seu discurso, a ideologia de sua ação. $\mathrm{O}$ velho sujeito atrelado à forma jurídico político discursiva, com seu corpo físico e consciência moral e ideológica, cede lugar de prioridade aos seus vários perfis que lhe são atribuídos de modo automático e alimentados por seus "traços" deixados cotidianamente.

Fazer com que os elementos da realidade se relacionem uns com os outros, não a partir da intervenção sobre eles, mas pela condução dos processos por meio do controle do ambiente. Com os dispositivos praticamente se substituem os indivíduos enquanto "objeto técnico-político de uma gestão e de um governo" (Foucault, 2008, p. 92). Os indivíduos passam a ser toda uma série de contingências e de dados de realidades distintas e específicas. Com isso, a ideia central e universal de uma norma do sujeito de direitos perde em eficácia. A multiplicidade de dados permite à ação de gestão da vida uma maior incidência, sobre os mínimos detalhes, e uma maior eficiência. Boa parte da eficácia dos dispositivos está em operar com o desejo dos indivíduos aparentando realizarem seus interesses. Como os algoritmos se propõem, facilitam, tornam os deslocamentos em direção a determinados desejos viáveis, e até mesmo inevitáveis, a adesão dos indivíduos será a própria atualização da potência dos dispositivos.

A estratégia da correlação de dados visa adaptar os desejos dos indivíduos à oferta e às possibilidades inerentes à velocidade de circulação. Um exemplo

15 Maurizio Lazzarato, ao explicar as sujeições produzidas pelo neoliberalismo, fala das máquinas a-significantes, moleculares e afetivas, das quais o capitalismo necessita e produz. "Máquinas e semióticas a-significantes são capazes de 'ver' esses estratos, 'ouvi-los', 'cheirá-los', registrá-los, ordená-los e transcrevê-los, o que é impossível para os sentidos e a linguagem humana. Infinitamente pequenos e grandes, infinitamente rápidos e lentos, os estratos escapam aos nossos sistemas de percepção e linguagem. As semióticas a-significantes e as máquinas operam da mesma maneira com o mundo pré-verbal da subjetividade humana, habitado por semióticas não verbais, afetos, temporalidades, intensidades, movimentos, velocidades, relações impessoais e não atribuíveis a um eu e a um sujeito individuado e, desse modo, dificilmente apreensíveis pela linguagem" (Lazzarato, 2014, p. 78). 
simples é a solicitação de um carro no aplicativo de transporte urbano. Tão logo se abra a busca, ainda na fase em que se localiza de onde é feito o pedido, já aparecem um, dois ou três carros disponíveis. Depois que se aciona a chamada, verifica-se que o carro disponível está mais distante do que aparecia inicialmente (este é um caso mais comum em locais com menor oferta de veículos). "Tratase de suscitar o ato de compra no modo da resposta-reflexo a um estímulo de alerta que provoca um curto-circuito na reflexividade individual e na formação do desejo singular" (Rouvroy e Berns, 2015, p. 44). A imagem inicial de um carro nas proximidades acelera no usuário o desejo imediato pelo consumo do serviço, "aproveitando" a oferta e antecipando outro consumidor.

Vai-se ao ato sem passar pela elaboração do desejo. Com isso, eliminam-se as etapas da troca de opiniões e gostos que participariam da escolha. Os dados parecem produzir o benefício objetivo, dentro de condutas possíveis e efetivas, sem acionar as condições espaciais, temporais, subjetivas e significantes. A partir de dados "puros", em si mesmos a-significantes, o tratamento probabilístico visa ao controle preditivo dos eventos pela circulação acelerada. Evitam-se as formas de desvios subjetivos encurtando a distância espaço-temporal entre estímulo e "resposta-reflexo". A velocidade do fluxo dispensa os sistemas semióticos e significantes sem se desfazer deles. Qualquer que seja o significado dos dados, o agenciamento das máquinas algorítmicas será acionado.

$\mathrm{O}$ aspecto massivo, global, despersonalizado, não classificado dos dados, ainda que segmentados e armazenados, faz parecer que seus conteúdos estão totalmente dessubjetivados e sua análise parte de e produz a objetividade da ação:

[...] quer se trate de conservar o traço de uma compra, de um deslocamento, do uso de uma palavra ou de uma língua, cada elemento é reconduzido a sua natureza mais bruta, isto é, ser ao mesmo tempo abstraído do contexto no qual apareceu e reduzido a 'dado'. Um dado não é mais que um sinal expurgado de toda significação própria (ibidem, p. 39).

O caráter geral, massificado, sem significação faz com que os indivíduos deixem os dados por aí sem se importarem com seus destinos. Será a heterogeneidade, materialidade total e, ao mesmo passo, a estrutura fragmentária e a-significante, que formará a aparência de pouca intencionalidade no armazenamento, garantindo a objetividade de suas informações. Permanecer aparentemente anônimos, sem sentido, faz as pessoas deixarem seus "traços" à mercê dos Big Data. Os indivíduos têm seus desejos realizados e passam a se identificar com certa regularidade dos fenômenos com os quais se envolvem. Temse um conjunto de indivíduos não mais marcados por um território, uma norma, um cargo, uma identidade, mas definidos como uma espécie de bioaplicativos, dispositivos prontos para a produção e receptação de traços na Internet. 
Forma-se a ideia de que normatividades imanentes às correlações de dados reais não seriam uma prescrição para o comportamento humano. Seria como uma descrição objetiva dos atos, seja de indivíduos ou de grupos, relacionados a partir do que foi enviado, recebido ou deixado nos Big Data. Em extremo, cria-se a lógica do fim da ética, do comportamento e das relações sociais em favor da verdade e da objetividade dos atos em si. Produz-se uma política preditiva, determinando decisões com base nos processos autômatos, eliminando quase por completo uma característica fundamental da ação política, o risco de sua imprevisibilidade. ${ }^{16}$ E este é o elemento sedutor dos algoritmos, o de que estaríamos construindo uma vida mais segura, estável e produtiva. O humano se tornaria parte do mecanismo das máquinas e tecnologias de dados.

\section{Indivíduo e o perfil maquínico}

Diferenciando-se das definições de servidões forçadas ou voluntárias, Gilles Deleuze e Félix Guattari desenvolveram o conceito de "servidão maquínica", na qual os indivíduos não seriam mais seres singulares, vítimas da opressão ou meros consumidores, mas partes integrantes dos servomecanismos. Seria a servidão ${ }^{17}$ maquínica o regime produtivo que atinge o indivíduo desordenando suas representações e comportamentos originados na e pela sujeição social. Esta produção refere-se a estratégias de máquinas tecnológicas e sociais nas quais componentes humanos e não humanos interagem e conformam os agenciamentos da vida cotidiana. Comparativamente à servidão maquínica, Deleuze e Guattari definiram a sujeição social:

Distinguimos como dois conceitos a servidão maquínica e a sujeição social. Há servidão quando os próprios homens são peças constituintes de uma máquina, que eles compõem entre si e com outras coisas (animais, ferramentas), sob o controle e a direção de uma unidade superior. Mas há sujeição quando a unidade superior constitui o homem como um sujeito que se reporta a um objeto que deveio exterior, seja esse objeto um animal, uma ferramenta ou mesmo uma máquina: o homem, então, não é mais componente da máquina, mas trabalhador, usuário..., ele é sujeitado à máquina, e não mais submetido pela máquina (2012, pp. 167-168).

16 Para Hannah Arendt, a ação é imprevisível, pois resulta da relação social entre sujeitos singulares e discursos dissonantes e, por mais que se criem modos de estabilizar as profundas diferenças - como, por exemplo, as leis -, não se poderia predizer o ato (2010, pp. 248-59).

17 Segundo explica Maurizio Lazzarato, servidão é um termo que Deleuze e Guattari encontraram na cibernética e na automação: “[...] ela significa a 'pilotagem' ou o 'governo' dos componentes de um sistema. Um sistema tecnológico subjuga ('governa' ou 'pilota') variáveis (temperatura, pressão, força, velocidade, resultado etc.) assegurando coesão e o equilíbrio funcional do todo. A servidão é o modo de controle e regulação ('governo') de uma máquina social ou técnica, como uma fábrica, uma empresa ou um sistema de comunicações. Ela recoloca a 'servidão humana' dos antigos sistemas imperiais (egípcio, chinês etc.), e por conseguinte é um modo de comando, de regulação e de governo 'assistido' pela tecnologia, constituindo, como tal, uma especificidade do capitalismo" (2014, pp. 28-29). 
O indivíduo não seria somente alguém que faz uso de algo ou age em algum acontecimento, se "usar" ou "agir" estiver relacionado ao sujeito. Geridos pela servidão, ele se constitui como ponto de junção, encontro, consumação de processos sociais, econômicos e políticos, por meio de inputs e outputs. Submetidos como máquinas humanas, os indivíduos "não são mais consumidores ou usuários, nem mesmo sujeitos que supostamente a 'fabricam', mas peças componentes intrínsecas, 'entradas' e 'saídas'. [...] Na servidão maquínica há tão-somente transformações ou trocas de informações das quais umas são mecânicas e outras humanas" (ibidem, p. 170).

Se na sujeição social há a produção de indivíduos que se comunicam com outros por meio da lógica sujeito/objeto, mediados por dispositivos externos a si (mídia, organizações políticas, discurso dos direitos humanos, Estado), na servidão maquínica o indivíduo se torna "dividual". A servidão não está limitada aos dualismos palavra/coisa, natureza/cultura, sociedade/Estado, objeto/ sujeito. $\mathrm{O}$ dividual não se encontra externo às máquinas e aos dispositivos do capitalismo, mas é ele próprio um componente produtivo de funções e estratégias dos processos políticos e perfilizados. Teríamos a leitura direta, sem intermediações, dos desejos e interesses do indivíduo, aferindo o saber do singular e padronizando seu comportamento por meio das funções algorítmicas:

[...] Imensos bancos de dados funcionam como dispositivos de marketing. Eles reúnem, selecionam e vendem milhões de dados sobre nosso comportamento, aquisições, hábitos de leitura, filmes favoritos, gostos, roupas e preferências de comida, assim como o modo como passamos nosso 'tempo livre'. Essas informações concernem os 'dividuais', cujos perfis, compostos pelo cruzamento desses dados, são meros relés de entradas e saídas, de input e output nas máquinas de produção-consumo (Lazzarato, 2014, pp. 37-38).

Os indivíduos, ao fazerem uso de serviço de cartões, celulares, ou de qualquer dispositivo conectado aos Big Data, imaginam seus perfis nas estruturas de informações a partir de uma individualidade. Contudo, há uma profícua organização de saberes a partir da formação de perfis que, apesar de não serem perceptíveis aos indivíduos ou ao público, tornaram-se a base da política maquínica. O perfil reúne traços deixados pelos indivíduos, mas não se configura como a expressão do "quem" o indivíduo é. Caracteriza-se mais por padrões de individualidades, categorizando costumes, hábitos, respostas-reflexo, ideologias, afetos e comportamentos psíquicos. Contribui para predizer em vez de buscar causas. Antecipa o agir dos similares, dentro de uma gama de variáveis, no lugar de vigiar o que fazem os singulares. Refletindo com Fernanda Bruno, podemos questionar "o que um tal conhecimento pode dizer sobre os indivíduos": 
De fato, ele diz menos sobre indivíduos pessoalmente identificáveis (ou seja, sobre "quem" são estas pessoas do ponto de vista de suas identidades civis) do que sobre suas ações, condutas, escolhas, as quais podem ser consequentemente suscitadas, desviadas, orientadas, conjuradas. Se há uma individualidade vinculada a esse tipo de rastro e ao conhecimento que se pretende gerar a partir dele, ela é menos da ordem do passado que do futuro, menos da ordem da interioridade que da exterioridade, menos relativa a uma singularidade do que a regras de similaridade (2013, p. 163).

Antecipa-se o comportamento dos indivíduos, ou mesmo de coletivos, nas mais diversas formas de existência humana (na medicina, no transporte público, na obtenção de crédito, nos sites de venda online).

O datamining e a elaboração algorítmica de perfis, em sua relação aparentemente não seletiva com o mundo, parecem levar em consideração a integridade de cada real até em seus aspectos os mais triviais e insignificantes, colocando todo o mundo em igualdade - o homem de negócios e a diarista, o sikh e o islandês (Rouvroy e Berns, 2015, p. 41).

As redes sociais e seus usuários são atravessados por semióticas significantes e formas políticas discursivas. Porém, são as funções e as operações de controle da circulação dos "estratos" mais lapidados e rústicos das máquinas que produzem maiores efeitos sobre as condutas. Antoinette Rouvroy (2014) sustenta mesmo que as redes sociais, longe de determinarem algo como o "fim do indivíduo" (ou da individualidade e da privacidade), produzem "hipersujeitos". Segundo a autora, é fato que se enfraquecem os limites de proteção à intimidade e à vida privada, o que poderia acarretar perdas de autonomia e livre arbítrio. Contudo, isso não seria totalmente evidente. Há certos dispositivos que protegem e, inclusive, isolam o indivíduo e sua privacidade (algumas redes, por exemplo, trabalham com mensagens criptografadas). Bem como algumas interfaces inteligentes, ao nos dispensar de uma série de atividades de trabalho, de escolhas e de execução de funções, poderiam nos fazer dispor de tempo livre para atividades intelectuais, políticas e processos criativos.

Toda a movimentação em torno do risco de acesso às informações pessoais, íntimas, privadas expostas às divulgações ou aos usos inadequados, com a perda de controle dos indivíduos sobre seus perfis, ensejou o desenvolvimento de uma série de legislações de proteção do indivíduo e de seus dados de natureza pessoal. São os casos da "Lei do esquecimento", ${ }^{18}$ na União Europeia, e do "Marco Civil", ${ }^{19}$ no Brasil.

18 Após decisão do Tribunal de Justiça da União Europeia, em maio de 2014, determinando o direito de se apagar dos sistemas de busca dados indesejados ou desatualizados (right to be forgotten), o Parlamento Europeu transformou em lei este direito. Um detalhamento maior da legislação europeia sobre o tratamento automatizado de dados pode ser acessado em "Des donnes et des hommes" (Rouvroy, 2016).

19 Lei que regula o uso da Internet no Brasil, com os princípios, direitos e deveres, bem como a atuação do Estado. Aprovada e sancionada em 2014, o "Marco Civil da Internet" no Brasil é considerado modelo na 
A importância e o papel das legislações protetivas dos dados de usuários e "seus" perfis nos interessa para retomar a discussão acerca do estatuto do indivíduo e do regime de produção de subjetividades. Considerando que as funções de governo coletam quantidades massivas de dados "automaticamente", isto é, sem a necessidade de consentimento de um indivíduo, há um desinvestimento na singularidade de nossa existência. E esta é uma questão política na medida em que produziria não uma dissolução do indivíduo, mas uma rarefação dos processos de subjetivação, tornando complexas e inacessíveis as oportunidades de nos constituirmos enquanto sujeitos.

Estaríamos diante de um processo de esquiva das subjetivações no quadro normativo da governamentalidade. Constata-se que a deliberação do indivíduo sobre a transmissão de informações é fraca e se dilui em proporção inversa à quantidade massiva de cliques e touchs. Assim, estes dados não estariam sendo "roubados", o que concretamente poderia gerar atos de resistência e demandas por direitos (fato que, em certa medida, pequena, tem gerado e produzido leis como as já citadas). Considerados triviais, descontextualizados, segmentados o bastante para se deixarem "perder" nos caminhos da rede, os traços seguem percursos incontroláveis para os sujeitos. E mais, estes dados produzem saberes extraídos diretamente da grande massa de informações e provêm de hipóteses (funções algorítmicas) que emergem dos próprios dados.

Dessa forma, a ação normativa surgida das estatísticas produz efeitos sobre os ambientes e processos. Aparentemente, os saberes preservariam os indivíduos, pois não haveria uma predominância de processos discursivos e significantes de subjetivação. A ação do indivíduo "não é mais influenciada por confrontação direta com uma norma exterior - lei, média, definição de normalidade -, mas suas possibilidades são organizadas no próprio seio de seu ambiente” (Rouvroy e Berns, 2015, p. 47). A potência de condução da vida estaria justamente na capacidade de não usar os sujeitos diretamente como suporte e apoiando-se na autonomia e indiferença quanto ao caráter dos dados. $\mathrm{O}$ fato de a unidade singular tornar-se somente um bioaplicativo, input e output de informações cujos processos ocorrem independentemente das escolhas políticas e ideológicas, é a garantia de eficácia das normatividades imanentes dos algoritmos.

\section{Predizendo por meio de estratégias autoritárias}

A governamentalidade algorítmica trabalha como uma memória do futuro, por meio de uma realidade aumentada pela percepção do presente com o uso de 
dados sem qualquer relação e sem significantes de pertencimento. Tal amplitude fornece às formas de governo por algoritmos a objetividade da percepção antecipada de um acaso sistematizado. O real e o possível apresentam-se aos sujeitos de modo que a eles cabe apenas se deixarem conduzir para os caminhos "naturais", aparentemente individualizados, porque provêm do perfil do usuário, e corretos, pois é a própria leitura da realidade, objetivada e sem interferências subjetivas, discursivas ou ideológicas. Do ponto de vista da democracia liberal, o governo via algoritmos aparece como objetivo, inofensivo, "posto que fundado sobre uma realidade anterior a toda manifestação de entendimento ou de vontade subjetivos, individuais ou coletivos, [...] alimentando o sonho de um governo perfeitamente democrático" (ibidem, p. 48).

Não havendo projeto prévio, com os sujeitos e os processos de subjetivação sendo evitados, qual seria o objeto da governamentalidade algorítmica? São as relações constituintes dos ambientes de produção capitalista. "Os dados transmitidos são relações e apenas subsistem enquanto relações; os conhecimentos gerados são relações de relações; e as ações normativas que daí decorrem são ações sobre as relações (ou ambientes) referidas às relações de relações" (ibidem, p. 49). A potência de criar uma realidade é tão grande quanto sua capacidade de registrar os dados. Seus mecanismos suscitam desejos e necessidades de consumo e de posições políticas e ideológicas, despolitizam mediante a anulação das subjetividades políticas, diminuindo as esferas do debate, das escolhas, da diversidade. $\mathrm{O}$ encontro com o outro, diferente, sujeito da anomalia e capaz de produzir as novas sociabilidades é evitado por meio das bolhas formadas via perfis.

O sujeito de direitos faz de sua luta e existência a efetivação da igualdade e da justiça por meio do poder soberano e de suas instituições. O corpo individual reproduz o treinamento social e físico ao qual é submetido nos equipamentos disciplinares. O indivíduo confessional, para quem "tudo deve ser dito", ativa "mecanismos de poder para cujo funcionamento o discurso [...] passou a ser essencial" (Foucault, 2011, p. 29). Nenhuma das formas de lidar com as relações de poder, em funcionamento e com percursos próprios, deixa de se encontrar nas estratégias autoritárias de controle e dominação. A governamentalidade algorítmica acrescenta-se a estes processos já existentes e configura-se, diferentemente dos outros modos, como um governo desprovido de projeto. Com isso, o foco descola-se das ideias de legitimidade na condução do projeto ou da verificação de sua aplicação. Ganham em importância os resultados e a concepção de processo, com a ocorrência de fracassos e de um fazer efetivo, estando sempre aberto às modificações e adaptações à "realidade".

Há várias iniciativas, científicas, comunicacionais e sociais, nas quais os Big Data exercerão uma função positiva. As aberturas propiciadas pela 
tecnologia massiva de dados possibilitam o acesso a informações e redes colaborativas, aumentando a potência de reflexão e de produção de saberes comuns e específicos. Contudo, elas vêm acompanhadas de fechamentos e controles, especialmente na medida em que os algoritmos são fabricados por grandes empresas e monopólios dos sistemas de comunicação. Este é um dilema que se apresenta, pois na governamentalidade "não se age, não se cria, modelase" (Parra, 2016). Ainda mais levando-se em consideração que o acesso aos dados deixados produz informações sobre perfis mesmo se não identificados. Ocorre um definhamento, quando não a eliminação direta, das deliberações públicas e das reflexões plurais e diversificadas. O saber que emerge aparece como verdade real, imparcial e indubitável dos traços deixados pelos indivíduos. A divergência política, o dissenso coletivo, as resistências e contestações sofrem a invisibilidade e a inoperosidade.

\section{Referências}

ARENDT, H. “A condição humana". Tradução de Roberto Raposo. Revisão técnica e apresentação A. Correia. Rio de Janeiro: Forense Universitária, 2010.

BRUNO, F. "Máquinas de ver, modos de ser: vigilância, tecnologia e subjetividade". Porto Alegre: Sulina, 2013.

CANGUILHEM, G. "O normal e o patológico". Tradução de M. T. R. de C. Barrocas. Rio de Janeiro: Forense Universitária, 2002.

DELEUZE, G. "Foucault”. Tradução de C. S. Martins. São Paulo: Brasiliense, 2006.

. "O ato de criação". Tradução de J. M. Macedo. Folha de S.Paulo, 27 de junho de 1999, pp. 4-5 [Online]. Disponível em http://intermidias.blogspot.com.br/2007/07/oato-de-criao-por-gilles-deleuze.html (Acessado em 05 de dezembro de 2016).

. Transcrição de conferência realizada em 17 de maio de 1987 (Qu'est-ce que l'acte de création?). Vídeo disponível em http://www.dailymotion.com/video/ x1dlfsr_gilles-deleuze-o-que-e-o-ato-de-criacao-legendas-em-portugues_creation (Acessado em 05 de dezembro de 2016).

DELEUZE, G., GUATTARI, F. "Mil platôs: Capitalismo e Esquizofrenia". Vol. 5. Tradução de P. P. Pelbart e J. Caiafa. São Paulo: 34, 2012.

FOUCAULT, M. "História da sexualidade I. A vontade de saber". Tradução de M. T. C. Albuquerque e J. A. G. Albuquerque. Rio de Janeiro: Graal, 2011.

. "Segurança, Território, População. Curso dado no Collège de France (1977-

1978)". Tradução de E. Brandão. São Paulo: Martins Fontes, 2008.

. "Le jeu de Michel Foucault". (pp. 298-329). In: Dits et Écrits II. 1976-1988.

Paris: Gallimard, 2001.

. "A ordem do discurso: aula inaugural no Collège de France". Tradução de L.

F. A. Sampaio. São Paulo: Loyola, 1996.

GUATTARI, Félix. "Caosmose: um novo paradigma estético". Tradução de A. L.

Oliveira e L. C. Leão. São Paulo: 34, 2012. 
LATOUR, B. "Jamais fomos modernos". Tradução de C. I. Costa. São Paulo: 34, 2013. LAZZARATO, M. "Signos, máquinas, subjetividades". Tradução de P. D. Oneto. São Paulo: Sesc e n-1, 2014.

LOTRINGER, S., MORRIS, D. (orgs.). "Schizo-Culture. The Event, The Book". In: Semiotext(e) Journal, 2 Vol. Set, 2014. [Esta publicação inclui um fac-símile da edição original, "The Book 1978", e a transcrição das conferências do evento, "The Event 1975", além de textos anteriores e posteriores ao "Schizo Culture"].

PARRA, H. "Abertura e controle na governamentalidade algorítmica". Revista Ciência e Cultura, São Paulo, Vol. 68, Nr. 1, Março de 2016 [Online]. Disponível em http://cienciaecultura.bvs.br/scielo.php?script=sci_arttext\&pid=S000967252016000100013\&lng=en\&nrm=iso (Acessado em 28 de novembro de 2016).

Rancière, J. "O desentendimento. Política e filosofia”. Tradução de Â. L. Lopes. São Paulo: 34, 1996.

ROUVROY, A. "Des donnes et des hommes. Droits et libertes fondamentaux dans um monde de donnes massives". Strasbourg, Conseil de L'Europe, 2016.

. "BigData: de nouveaux outils à combiner aux savoirs établis et à encadrer par la délibáration publique". Revue Statistique et Société, Société Française de Statistique (SFdS), França, Vol. 2, Nr. 4, Dezembro de 2014.

" "Algorithmic Governmentality and the End(s) of Critique". Conference Society of the Query \#2, Main Building Amsterdam Public Library (OBA), Amsterdam, Holanda, 08 de Novembro de 2013 [Online]. Disponível em https://vimeo.com/79880601 (Acessado em 05 de dezembro de 2016).

. "Technology, Virtuality and Utopia. Governmentality in an Age of Autonomic Computing". (pp. 119-140). In: M. Hildenbrandt, A. Rouvroy (eds.). Law, Human Agency and Autonomic Computing. Philosophers of Law Meet Philosophers of Technology. Routledge, 2011.

ROUVROY, A., BERNS, T. "Governamentalidade algorítmica e perspectivas de emancipação: o díspar como condição de individuação pela relação?”. Tradução de P. H. Andrade. Revista Eco Pós, Rio de Janeiro, UFRJ, Vol. 18, Nr. 2, pp. 36-56, 2015. SAFATLE, V. "O circuito dos afetos. Corpos políticos, desamparo e o fim do indivíduo". São Paulo: Cosac Naify, 2015.

SUSTEIN, C. R. "Republic 2.0”. Princeton University Press, 2009.

VIRILIO, P. "Banlieues en crise. La gripe viaire”. Revue Urbanisme, n. 347, Março-Abril de 2006. Disponível em https://www.urbanisme.fr/mobilites-exclusions/magazine-347/ AGORA (Acessado em Novembro de 2016). 